\title{
Uma Análise sobre a Produção de Conhecimento Científico nas Pesquisas Publicadas nos Primeiros 10 anos da iSys (2008- 2017)
}

\section{Title: An Analysis of the Production of Scientific Knowledge in Research Published in the First 10 years of iSys (2008-2017)}

\author{
Renata Araujo ${ }^{1}$, Marcelo Fornazin ${ }^{1,2}$, Mariano Pimentel ${ }^{1}$ \\ ${ }^{1}$ Programa de Pós-Graduação em Informática - Universidade Federal do Estado do Rio \\ de Janeiro (UNIRIO) \\ ${ }^{2}$ Instituto de Computação - Universidade Federal Fluminense (UFF). \\ \{renata.araujo,pimentel\}@uniriotec.br, fornazin@ic.uff.br
}

\begin{abstract}
One of the challenges faced by the Information Systems Brazilian scientific community, emerged from the Computing area, has been how to deal with Information Systems (IS) research, which involves aspects beyond computational technology building. Advances in producing scientific knowledge in IS requires mastery and application of theories, paradigms and methods underexplored. We have analyzed the research published during the first 10 years on iSys journal in order to reflect on possible theoretical, epistemological and methodological approaches to IS research. The analysis was based on typologies used in the international literature, comprising four axes: i) IT artifact design, ii) research paradigm, iii) theorization, and iv) research methods. Our observations found out that the IS research community at iSys puts a strong positivist and experimental emphasis in the production of scientific knowledge. These results may encourage the IS community towards different epistemological paradigms to better understand the complexity and multiplicity of the real world; as well as the formulation of a consistent theoretical field for the research area.
\end{abstract}

Keywords. Knowledge Production in IS; Theory; Epistemology; Methodology.

Resumo. Um dos desafios da comunidade cientifica brasileira de Sistemas de Informação (SI) ligada à Computação tem sido endereçar a pesquisa em SI, que vai além da construção de tecnologias computacionais. O avanço da produção do conhecimento científico em SI passa pelo domínio e aplicação de teorias, multiplicidade de paradigmas e métodos de pesquisa que ainda são pouco explorados. Realizamos uma análise das pesquisas publicadas na iSys, ao longo dos primeiros 10 anos, com o intuito de refletir sobre possíveis

Cite as: $\quad$ Araujo, R., Fornazin, M. \& Pimentel, M. (2017). Uma Análise sobre a Produção de Conhecimento Científico nas Pesquisas Publicadas nos Primeiros 10 anos da iSys (2008-2017) (An Analysis of the Production of Scientific Knowledge in Research Published in the First 10 years of iSys (2008-2017)). iSys: Revista Brasileira de Sistemas de Informação (Brazilian Journal of Information Systems), 10(4), 45 65 . 
caminhos teóricos, epistemológicos e metodológicos para as pesquisas de SI. A análise se baseou em tipologias empregadas pela literatura internacional, compreendendo quatro eixos de análise: i) concepção do artefato TI, ii) paradigma de pesquisa, iii) teorização, e iv) métodos de pesquisa. Como principais conclusões desta análise, observamos por parte da comunidade de pesquisa em SI na iSys, a produção de conhecimento científico com forte ênfase positivista e experimental. A análise aponta para caminhos e oportunidades para robustecer a produção de conhecimento nacional que incluem a abertura a paradigmas epistemológicos que compreendam a complexidade e a multiplicidade do mundo real e a formulação de um campo teórico consistente para a área.

Palavras-Chave. Produção de Conhecimento em SI; Teoria; Epistemologia; Metodologia.

\section{Introdução}

A presença da tecnologia nos mais diversos cenários de atuação humana - sociais, culturais, políticos e de negócios - levam a quase todas as áreas de prática e de pesquisa hoje à necessidade de compreender a configuração e a dinâmica dos sistemas de relações que se estabelecem com a presença de agentes humanos e tecnológicos. Desse modo, configuram-se os sistemas de informação baseados em tecnologia, que chamaremos mais simplesmente neste artigo de Sistemas de Informação (SI). Assim, a pesquisa na área de SI busca compreender, de forma interdisciplinar, como indivíduos e organizações interagem com a tecnologia na busca de soluções a problemas de negócios, governos e da sociedade em geral. Além disso se propõe a promover novas interações e inovações para a negócios, governos e a sociedade em geral.

Historicamente, seguindo os enquadramentos dos sistemas acadêmicos que demandam a necessidade de contorno de áreas delimitadas de pesquisa, a pesquisa de SI no Brasil foi se configurando de forma mais explícita sobretudo pela perspectiva de duas áreas acadêmicas distintas. Por um lado, a Administração tem se dedicado ao estudo dos efeitos de sistemas de informação em contextos sociais e organizacionais, e por outro, a Computação, enfoca o estudo das melhores formas de construção de sistemas tecnológicos e computacionais para atendimento a demandas organizacionais ou sociais. Concordamos com vários autores que, há tempos, discutem que as distinções entre essas áreas acadêmicas têm sido um dos principais obstáculos para uma visão científica capaz de abordar a complexidade do mundo contemporâneo, tanto na ciência em geral [Capra e Luisi, 2014][Morin, 2005][Latour, 1997] quanto na área de SI [Cukierman, Teixeira, e Prikladnicki, 2006][Orlikowski e Iacono, 2001].

Como pesquisadores na área de Sistemas de Informação, tanto na perspectiva da Computação como da Administração, temos nos dado conta que o potencial da pesquisa científica em SI para a sociedade está, não na delimitação de áreas, mas na capacidade de ação conjunta para a compreensão de problemas e na aplicação de abordagens sólidas de pesquisa que possam trazer à luz da sociedade soluções efetivas para as questões complexas que vemos hoje no mundo. Em nossa trajetória, estivemos acompanhando de forma mais próxima, há quase duas décadas, a evolução da comunidade científica em SI no contexto da comunidade nacional de Computação [Araujo et al., 2015]. Será sob esta perspectiva que trabalharemos nossas análises neste artigo, na expectativa principalmente de que possamos trazer algumas reflexões para essa nossa comunidade científica de sistemas de informação. 
Nossa preocupação data de 2009, quando a comunidade de pesquisa em Sistemas de Informação vinculada à Sociedade Brasileira de Computação $(\mathrm{SBC})^{1}$ elabora uma agenda de ações para os dez anos subsequentes [Cidral et al., 2009]. Nesta agenda, cinco questões foram apontadas para a área, sendo que no presente artigo discutiremos, de alguma forma, três daquelas questões: i) a definição de referencial teórico para a pesquisa em SI, que possa caracterizar suas principais questões e permitir flexibilidade para aplicação em domínios diversos e de constante evolução, de acordo com os avanços tecnológicos e sociais; ii) a abertura à múltipla disciplinaridade, caracterizando níveis de relevância e rigor necessários à pesquisa desta natureza; e iii) o desenvolvimento de competências em diferentes metodologias de pesquisa, tanto quantitativas quanto qualitativas, mas com ênfase no rigor e relevância da sua aplicação, para a obtenção de contribuições científicas efetivas para a área e para a sociedade em geral. $\mathrm{O}$ desafio está em como tratar a complexidade inerente à pesquisa nessa área, por sua característica multidisciplinar e exigência de aplicação prática, tornando necessária a compreensão, domínio e utilização de abordagens de pesquisa não comuns à área de Computação até então [Recker, 2013]. Isto é absolutamente necessário para que possa subsidiar aquilo que constitui a sua própria razão de ser e sua contribuição social: investigar as possibilidades de soluções tecnológicas sistêmicas para problemas complexos no mundo real em diferentes domínios de aplicação.

Gostaríamos de contribuir com o que acreditamos ser um passo importante para enfrentar esse desafio, refletindo sobre a forma como a comunidade brasileira em SI tem gerado conhecimento científico. Consideramos que a Revista Brasileira de Sistemas de Informação (iSys) é atualmente uma das revistas de referência para a publicação da comunidade científica nacional em SI, sobretudo a que emerge da área da Computação ${ }^{2}$. Seu conteúdo representa, de forma significativa, o reflexo das pesquisas desenvolvidas por essa comunidade. Aproveitando a edição comemorativa de seus 10 anos de existência, analisamos a produção de conhecimento científico de todos os artigos publicados nesta primeira década da revista (Seção2).

Nossa análise foi inspirada em categorias previamente empregadas em investigações encontradas na literatura internacional [Orlikowski e Iacono, 2011] [Hirscheim e Klein, 1989][Heeks e Bailour, 2007][Palvia et al., 2017]. Organizamos nossas análises em quatro eixos. O primeiro deles envolve a Concepção do Artefato TI (Seção 3), em que temos a intenção de analisar de que perspectiva as tecnologias de informação estão sendo conceituadas nas pesquisas publicadas na iSys. Desejamos caracterizar qual a visão e intensidade de contato da pesquisa com o artefato tecnológico - como uma ferramenta aplicada à solução de um problema identificado (caixa-preta), em seu aspecto computacional interno (caixa-branca), se é somente nominado mas não se torna o objeto específico da pesquisa, se o interesse da pesquisa é em uma faceta de seu uso, ou se é problematizado de forma conjunta e indissociável com seu contexto de uso. O segundo eixo aborda a Fundamentação Teórica das pesquisas (Seção 4). Tratamos de codificar em que nível teórico as pesquisas se fundamentam. Entendemos que uma teoria compreende uma estrutura de categorias e relacionamentos que explicam um determinado fenômeno do mundo, verificadas e confirmadas por diferentes pesquisadores, obtendo aceitação e legitimidade em uma comunidade de pesquisa. Em um terceiro eixo - Paradigmas de Pesquisa (Seção 5) - temos a intenção de identificar

\footnotetext{
${ }^{1}$ Sociedade Brasileira de Computação - www.sbc.org.bt

2 Comissão Especial de Sistemas de Informação (SBC) - http://www2.sbc.org.br/ce-si//
} 
a frequência das diferentes perspectivas epistemológicas das pesquisas publicadas na iSys: positivista, interpretativa, projetiva, crítica ou sociotécnica. Com essa análise, queremos refletir sobre a apropriação pela comunidade de pesquisa das diferentes perspectivas epistemológicas, incluindo aquelas que podem oferecer novas maneiras de pensar a complexidade do mundo atual. No quarto e último eixo - Métodos de Pesquisa - mapeamos os métodos de pesquisa utilizados na condução das pesquisas publicadas na iSys: experimento, survey, estudo de caso, simulação etc (Seção 6). Gostaríamos de observar, além de mapear a ocorrência dos métodos, como estes se alinham com os paradigmas de pesquisa empregados (analisados no eixo anterior). Ademais, relacionamos os resultados obtidos de nossa análise dos artigos iSys com algumas análises sobre os artigos publicados nas principais revistas internacionais de Sistemas de Informação. Essas análises nos ajudaram a pensar a respeito de oportunidades para o robustecimento da produção de conhecimento nacional (Seção 7), para o aperfeiçoamento do fazer científico, visando contribuir para o amadurecimento de nossa comunidade de pesquisa.

\section{Método de análise}

A nossa análise sobre como a comunidade brasileira em SI tem gerado conhecimento científico foi baseada nas publicações da revista iSys, um importante periódico voltado para a produção acadêmica em SI. Nesta seção apresentamos uma breve contextualização da revista iSys e da base de dados produzida para análise, bem como os procedimentos de codificação e classificação dos artigos.

A revista iSys ${ }^{3}$ foi criada em 2008 dentro do Programa de Pós-Graduação em Informática da Universidade Federal do Estado do Rio de Janeiro (UNIRIO) ${ }^{4}$, que é o primeiro programa de pós-graduação em Computação no Brasil que se propõe a estabelecer como área de concentração em pesquisas, a área de Sistemas de Informação. A iSys foi concebida para ser um fórum de publicação das pesquisas científicas em Sistemas de Informação no Brasil. A submissão à iSys ocorre por demanda contínua, através de artigos científicos, mas também por versões estendidas de artigos selecionados de eventos relacionados que são apoiados pela revista.

$\mathrm{Na}$ primeira edição da revista, foram publicados os melhores artigos do IV Simpósio Brasileiro de Sistemas de Informação (SBSI), realizado no ano de 2008, evento promovido pela Sociedade Brasileira de Computação (SBC); e desde então, em todos os anos subsequentes, os melhores artigos do SBSI são convidados a submeterem uma versão expandida na revista. Para dar mais visibilidade ao lançamento da primeira edição da revista, foram convidados renomados pesquisadores para a publicação de artigos "apresentando pontos de vista sobre Sistemas de Informação e pesquisas consolidadas que tangem o tema" [Barros et al., 2008, p.i]. Na segunda edição em diante, em vez de artigos convidados, passaram a ser publicados "artigos selecionados entre os trabalhos submetidos pelos pesquisadores da área diretamente para a iSys" fluxo contínuo [Barros et al., 2009, p.i], bem como versões estendidas de artigos publicados no SBSI e eventos relacionados - Brazilian Workshop on Social Network Analysis and Mining (BRASNAM), em 2014, e Workshop Anual do MPS (WAMPS), em 2015.

\footnotetext{
${ }^{3}$ iSys - Revista Brasileira de Sistemas de Informação - http://www.seer.unirio.br/index.php/isys

${ }^{4}$ PPGI-UNIRIO - http://www.uniriotec.br/ppgi
} 
Em 2010, é criada a Comissão Especial em Sistemas de Informação (CESI) ${ }^{5}$ na SBC, comissão essa responsável por representar a comunidade de pesquisa em SI no âmbito da SBC, bem como definir e executar ações estratégicas para a área a partir de então. $\mathrm{O}$ que se vê nas edições da iSys a partir deste ano é o reflexo da consolidação contínua desta comunidade, em particular com a organização de publicações provenientes do fórum permanente de discussão da área, o SBSI. Em 2013, a iSys passa a ter seus editores-chefe designados pela CESI, se tornando a revista oficial da comunidade de SI na SBC. Em 2016, são lançadas 4 edições especiais temáticas, cada uma delas abordando áreas demonstradas como de grande interesse pela comunidade de SI, incluindo a organização de workshops anuais - Gestão de Processos de Negócio, Governo Eletrônico, Educação em SI e Inovação em SI. Ainda em 2016, a CESI decide realizar o projeto de organização dos Grande Desafios da Pesquisa em Sistemas de Informação no Brasil (2016-2026) [Araujo, Maciel e Boscarioli, 2017], como forma de identificar as grandes questões de interesse em pesquisa pela comunidade. Para aumentar a sinergia da comunidade a respeito destes desafios, em 2017 iniciou-se o lançamento de edições temáticas da iSys contemplando cada um destes desafios. Até o momento de elaboração deste artigo, somente a edição temática "Abordagem Sociotécnica em Sistemas de Informação" havia sido publicada, ainda em 2017.

A revista manteve periodicidade de uma edição anual até 2013, e em 2014 em diante passou a ter periodicidade trimestral. Ao longo dessa primeira década da revista, foram publicados 103 artigos nas 20 edições da revista, resultando uma média de 5 artigos por edição. Na Figura 1, apresentamos a quantidade de artigos publicados por edição da revista iSys em sua primeira década de existência:

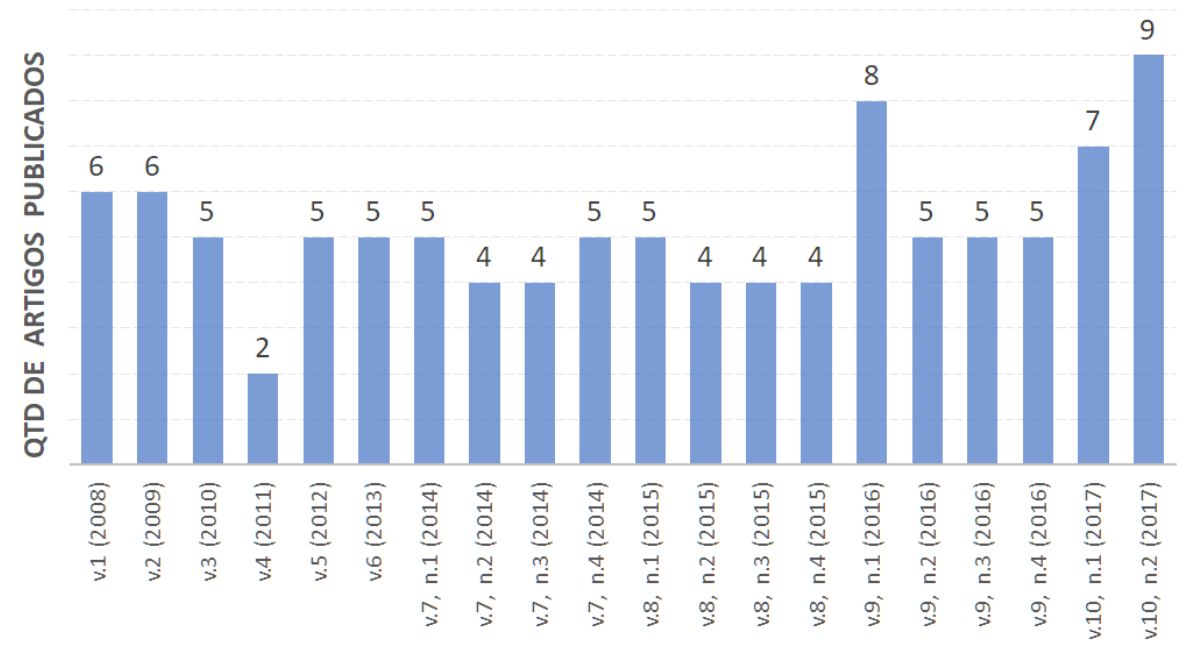

EDIÇÃO DA REVISTA ISYS

Figura 1 - Artigos publicados ao longo das edições na revista iSys, de 2008 a 2017

Baseados nas tipologias empregadas na análise da literatura internacional, elaboramos quatro eixos de análise para codificarmos os artigos publicados na revista iSys. Desse modo, analisamos o conjunto de artigos publicados na iSys a partir das seguintes abordagens: concepção do artefato TI [Orlikowski e Iacono, 2011], paradigma de pesquisa [Hirscheim e Klein, 1989], teorização [Heeks e Bailour, 2007] e métodos de pesquisa [Palvia et al., 2017]. As categorias de cada eixo foram descritas nas suas respectivas seções.

\footnotetext{
${ }^{5}$ Comissão Especial em Sistemas de Informação/SBC - http://www2.sbc.org.br/ce-si//index.html
} 
Com base nos critérios destes quatro eixos, elaboramos um processo de codificação que serviu de referência para análise dos artigos. O processo colocou como foco inicial a leitura do título e resumo de cada artigo, buscando extrair informações para a análise de cada eixo. Quando não foi possível codificar o artigo pelo seu título e resumo, também fizemos a leitura do artigo completo. Para a quase totalidade dos artigos, uma leitura completa, mesmo que transversal, foi realizada.

A codificação dos 103 artigos foi dividida entre os três autores de maneira intercalada, de modo que cada autor analisou artigos publicados em diferentes anos e edições da revista. Após a codificação individual, foram realizadas três sessões de revisão da codificação de modo a se debater os resultados e reduzir o viés pessoal de cada autor no processo de codificação.

\section{Concepção do Artefato TI}

Orlikowski e Iacono (2001) partem da premissa de que a Tecnologia da Informação (TI) é o tópico central dos estudos de SI e investigaram como as pesquisas da área conceituam a TI. Identificaram 14 conceituações de TI agrupadas em uma taxonomia com cinco enfoques sobre o artefato TI: ferramenta, computacional, faceta, nominal e conjunto.

$\mathrm{Na}$ concepção da TI como ferramenta (tool), considera-se que "a tecnologia, desse ponto de vista, é o artefato projetado com a expectativa de fazer o que seus projetistas esperam. Como tal, o que a tecnologia é e como funciona são vistos geralmente como questões técnicas (separadas, definíveis, imutáveis e sobre as quais os humanos têm controle)" (p.123), por exemplo, ferramentas para o aumento da produtividade, para o processamento de informação, e para mudança das relações sociais. Nessa perspectiva, busca-se investigar a TI como um objeto bem delimitado com objetivo de compreender os efeitos da interação entre o objeto TI e seu contexto como, por exemplo, aumento de desempenho, mudanças organizacionais etc. Cabe aqui ressaltar que, no enfoque de TI como ferramenta, há uma clara separação entre o artefato TI e o contexto de uso, os quais são compreendidos como entidades discretas que podem ser separadas e estudadas de forma independente.

As pesquisas com o enfoque computacional de TI (computational), são focadas no poder computacional da tecnologia de informação, e não estão interessadas na interação das pessoas com a tecnologia em diferentes contextos sociais. "Os artigos que têm essa visão estão interessados principalmente nas capacidades da tecnologia para representar, manipular, armazenar, recuperar e transmitir informações, e com isso apoiando, processando, modelando ou simulando aspectos do mundo" (p.127). Cabe aqui ressaltar que pesquisas enquadradas no enfoque computacional, embora se inspirem em problemas do mundo para construção de algoritmos ou simulações, não problematizam o contexto de uso do artefato TI.

A categoria faceta (tradução que adotamos para o que os autores denominaram de proxy), refere-se às pesquisas que "focalizam em um ou poucos atributos essenciais que representam um aspecto, propriedade ou valor que possa ser empregado para medir, comparar ou valorizar a tecnologia de informação" (p.124). Um exemplo do enfoque de faceta é o custo total de propriedade em TI (Total Cost of Ownership, TCO) que oferece uma medida do valor total necessário para se adquirir e manter um determinado recurso de TI em uma empresa, e essa medida possibilita comparar o custo entre diferentes empresas ou avaliar o custo de TI em comparação com outros recursos. Os atributos 
investigados nas pesquisas de faceta podem ser constituídos de medidas de capital (investimento, retorno, custo etc.), medidas de percepção (facilidade de uso e utilidade, por exemplo), ou ainda níveis de difusão da TI em um determinado contexto (organizacional, social ou econômico). As pesquisas de faceta buscam, portanto, construir atributos mensuráveis, os quais possibilitem a comparação da TI em diversos contextos e assim identificar regularidades entre empresas, setores econômicos e tipos de tecnologia.

Um outro grupo de pesquisas, nominado aqui enfoque conjunto (tradução que adotamos para o que os autores rotularam de ensemble), busca problematizar o artefato TI e seu contexto de uso considerando-os indissociáveis. Pesquisas que adotam o enfoque conjunto investigam "as interações dinâmicas entre pessoas e tecnologia - seja durante a construção, implementação ou uso em organizações, ou durante a implantação de tecnologia na sociedade em geral" (p.126). As pesquisas inspiradas nesse enfoque têm variações de ênfase no desenvolvimento ou no uso da TI em seu contexto, mas de um modo geral problematizam tanto a TI quanto o contexto de uso, levando em conta a complexidade e as questões sociais, econômicas, políticas etc. Desse modo, a visão conjunta se opõe às visões de ferramenta e faceta por considerá-las reducionistas.

Por fim, as pesquisas categorizadas no grupo nominal (nominal) "envolvem tecnologia 'apenas em nome, mas não de fato'. Normalmente, os termos 'tecnologia da informação', 'sistema de informação' ou 'computador' são usados algumas vezes nos artigos, mas essas referências à tecnologia são acessórias ou usadas como informação de fundo. A ênfase conceitual e analítica está em outra coisa, tipicamente focada em uma variedade de tópicos de interesse geral para o campo de Sistema de Informação. (...) Dessa forma, na perspectiva nominal, os artefatos de TI não são descritos, conceituados ou teorizados; tecnologia está essencialmente ausente desses artigos” (p.128). São artigos que tratam, por exemplo, da carreira de TI, ensino de SI etc.

Analisamos todos os artigos da revista iSys para identificar como a Tecnologia da Informação foi conceituada em cada pesquisa. Como resultado, na Figura 2 representamos a frequência de artigos em cada categoria dessa análise.

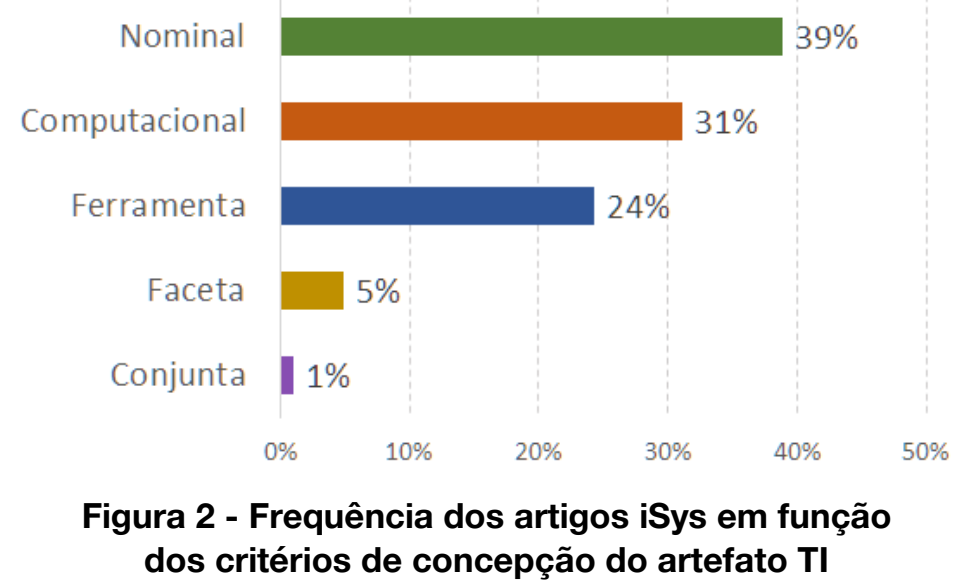

Observamos que as pesquisas publicadas na iSys, em sua maioria, desenvolvem pesquisas onde o artefato SI é nominado (Nominal, 38,8\%), o que reflete o interesse na discussão de temáticas relacionadas a SI, embora não diretamente trabalhem o artefato em si. Isto pode ser explicado pela associação ao longo dos anos das pesquisas em SI 
com as pesquisas na área Computação relacionadas a processos de produção de sistemas, à gestão organizacional e à gestão de TI. Ressaltamos o número de artigos que enxergam o artefato SI em sua característica Computacional $(31,1 \%)$, onde a problematização de contextos de aplicação do artefato SI não é evidente, seguindo uma visão vocacional da área de Computação em abstrair, simplificar e reduzir a complexidade dos contextos sociais e organizacionais. $\mathrm{O}$ número de artigos classificados como Ferramenta $(24.3 \%)$ aponta para um conjunto de pesquisas que visam resolver um problema em um dado contexto. $\mathrm{O}$ número bastante pequeno de publicações nas categorias Conjunta (1\%) e Faceta (4,9\%) nos faz refletir sobre as oportunidades de conceber a tecnologia sob perspectivas interdisciplinares para além do poder computacional ou como uma ferramenta.

Orlikowski e Iacono (2001) realizaram a análise de 177 artigos publicados na revista Information Systems Research (ISR) no período de 1990 a 1999. Tal categorização também foi empregada em análises mais recentes, como é o caso do Grover e Lyyntinen (2015) que analisaram outros 143 artigos publicadas nas revistas ISR e MIS Quarterly (MISQ) entre os anos de 1998 e 2012. Os resultados de ambas análises, bem como das análises dos artigos da iSys, são apresentados na Tabela 1.

Tabela 1 - Análise das pesquisas em relação ao enfoque do estudo do artefato TI

Fonte: Baseado em Orlikowski e Iacono (2001), Grover e Lyytinen (2015)

e dados obtidos pelos próprios autores

\begin{tabular}{lccc}
\cline { 2 - 4 } & $\begin{array}{c}\text { ISR } \\
1990-1999 \\
\text { (Orlikowski e } \\
\text { lacono, 2001, } \\
\text { p.128) }\end{array}$ & $\begin{array}{c}\text { ISR e MISQ } \\
\text { 1998-2012 } \\
\text { (Grovere } \\
\text { Lyyntinen, } \\
2015, \mathrm{p} .279)\end{array}$ & $\begin{array}{c}\text { iSys } \\
\begin{array}{c}\text { 2007-2017 } \\
\text { (Fonte: } \\
\text { própria dos } \\
\text { autores) }\end{array}\end{array}$ \\
\hline Nominal & $25 \%$ & $31 \%$ & $39 \%$ \\
Computacional & $24 \%$ & $12 \%$ & $31 \%$ \\
Ferramenta (tool) & $20 \%$ & $22 \%$ & $24 \%$ \\
Faceta (proxy) & $18 \%$ & $24 \%$ & $5 \%$ \\
Conjunto (ensemble) & $13 \%$ & $11 \%$ & $1 \%$ \\
\hline Total de Artigos & $\mathbf{1 7 7}$ & $\mathbf{1 4 3}$ & $\mathbf{1 0 3}$ \\
\hline
\end{tabular}

Dessa análise dos resultados, podemos constatar que na revista iSys, como também nas principais revistas internacionais de Sistemas de Informação, em torno de um terço dos artigos (31\% a 39\%) está na categoria Nominal: não trata da tecnologia em si, mas de questões de interesse da área. A tecnologia não é o único interesse das pesquisas na área de Sistemas de Informação, e os artigos publicados na revista iSys também refletem isso. Também constatamos que a visão da tecnologia enquanto ferramenta para uma determinada finalidade (tool) está presente em torno de $23 \%$ das pesquisas, tanto nos artigos publicados na revista iSys (24\%) quanto nas revistas internacionais $(22 \%)$.

Uma primeira diferença observada é que, nas revistas internacionais analisadas, a frequência de artigos publicados baseados na visão computacional, da década de 1990 para a década de 2000 caiu pela metade, aparecendo em apenas $12 \%$ dos artigos. Contudo, na revista iSys a visão computacional ainda é muito comum, aparecendo em 
$31 \%$ dos artigos. Outra diferença se manifesta em artigos baseados nas perspectivas de Faceta e de Conjunto, os quais estão presentes em 35\% dos artigos publicados nas revistas internacionais (frequência mantida aproximadamente estável em relação à década de 1990, em que essas categorias abrangeram 31\% dos artigos), na revista iSys essas perspectivas foram identificadas em apenas 6\% dos artigos. Esses resultados sugerem que a pesquisa internacional em SI tem valorizado também pesquisas em que a tecnologia é vista como faceta (uma medida) ou em conjunto (enfocando as interações dinâmicas entre pessoas e tecnologia), que requerem outras práticas de pesquisa mais comuns na Administração, Negócios e Economia.

Por fim, os trabalhos baseados na concepção de ferramenta têm potencial para promover a problematização do contexto de uso, sendo uma oportunidade para a nossa comunidade desenvolver competências para teorizar a produção científica relacionando tecnologia e seus contextos de uso.

\section{Fundamentação Teórica}

A construção de um corpo teórico pode ser compreendida como um dos objetivos de uma comunidade científica. Cidral e colaboradores (2009) propuseram o desafio de se definir um referencial teórico para a pesquisa em SI, que possa caracterizar suas principais questões e permitir flexibilidade para aplicação em domínios diversos e de constante evolução, de acordo com os avanços tecnológicos e sociais. Assim, esta seção busca refletir sobre o processo de teorização encontrado nos artigos publicados na iSys.

Para tanto, nos baseamos em Heeks e Bailur (2007) os quais propuseram uma categorização no que concerne ao uso de teorias para fundamentar as pesquisas em governo eletrônico. Ainda que Heeks e Bailur (2007) tenham analisado o cenário de governo eletrônico, acreditamos que o esquema de codificação por eles proposto é válido para analisar também a pesquisa em SI, visto que esses autores participam com grande intensidade no debate internacional de SI. Esses autores identificaram sete categorias, desde o uso de teorias gerais até a ausência de fundamentação teórica: teoria, framework, modelo, esquema, conceito, categoria, ateórico. Ao aplicarmos essas categorias para analisar as pesquisas publicadas na revista iSys, consideramos mais adequado agregar as categorias Framework-Modelo, e Conceitos-Categorias, porque consideramos que essas categorias eram próximas e nem sempre facilmente diferenciáveis. Também rebatizamos a categoria "esquema" para Técnica.

Com essas simplificações, chegamos a um sistema de classificação com cinco categorias. Artigos classificados na categoria teoria são artigos que empregaram uma teoria robusta, difundida e consolidada pela literatura. São exemplos de teorias utilizadas nas pesquisas em SI: Gerência de Processos de Negócios (BPM), Governança Corporativa, Sociedade em Rede, Teoria Institucional, Teoria Ator-Rede. As publicações classificadas como framework-modelo correspondem a artigos que fundamentaram a pesquisa em um framework derivado de um trabalho teórico, ou num modelo com conceitos e relacionamentos, os quais se propõem a explicar, prever ou prescrever um determinado fenômeno. Artigos enquadrados nessa categoria são os que discutem modelos de maturidade ou frameworks de práticas, por exemplo, CMMi, MPS.Br, Scrum etc. Pesquisas classificadas como Técnica (esquema) são artigos que fundamentaram a pesquisa em alguma técnica para resolução de um problema computacional. Em geral, nesses artigos são apresentados algoritmos ou técnicas, sem no entanto, problematizar o contexto de uso. Desse modo, não buscaram refletir sobre o 
SI a partir de uma teoria, framework ou modelo, mas sim avançar com um conhecimento técnico-computacional. Os artigos classificados como conceitoscategorias são os artigos que fundamentaram a pesquisa em conceitos, sem no entanto, fazer referência a uma teoria, framework ou modelo mais amplo. Aqui foram classificados, por exemplo, artigos que analisaram fatores de sucesso ou de influência de projetos de sistemas de informação, mas que não associaram esses fatores a explicações fundamentadas em teoria, framework ou modelo. Por fim, artigos classificados como ateórico foram os artigos que não fundamentaram a pesquisa em qualquer noção teórica, geralmente apresentam um sistema de informação ou um caso prático sem, no entanto, analisar o problema de pesquisa a partir de uma teoria, framework-modelo, técnica, ou conceitos-categorias. São pesquisas que apresentam contribuições para a prática da produção e uso de SI, sem avanços de teorização para a área.

Analisamos todos os artigos da revista iSys para identificar o tipo de fundamentação teórica de cada pesquisa. Como resultado, na Figura 3 representamos a frequência de artigos em cada categoria dessa análise.

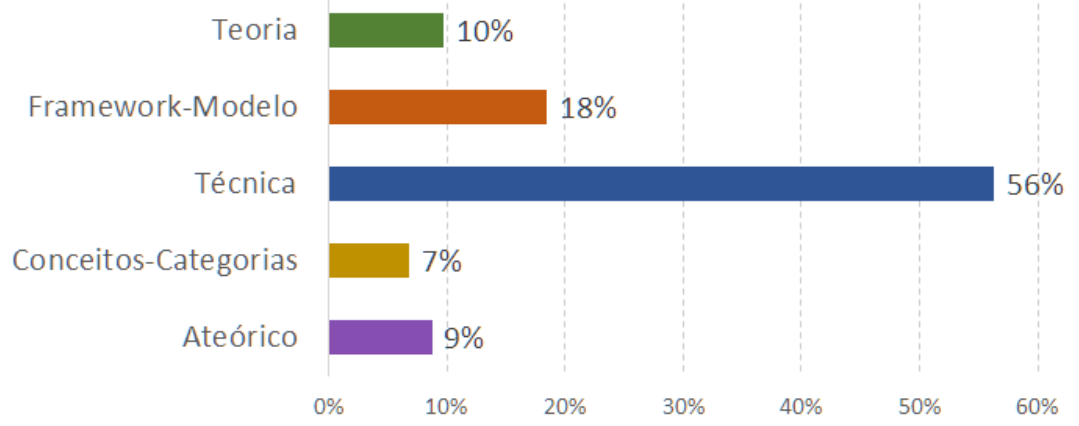

Figura 3. Frequência de artigos da iSys por tipo de fundamentação teórica

Do resultado dessa análise, constatamos que menos de um terço das pesquisas estão fundamentadas em teoria, framework ou modelo (28\%), que são as pesquisas que buscam compreender um fenômeno de SI a partir de um corpo teórico mais amplo. A maioria das pesquisas publicadas na revista iSys está fundamentada em técnicas - cabe aqui ressaltar que essas pesquisas não estabeleceram um diálogo com um corpo teórico mais amplo. 7\% das pesquisas está fundamentada em conceitos-categorias, e 9\% não apresentaram uma fundamentação teórica. Esses resultados nos levam a concluir que a maior parte das pesquisas publicadas na revista iSys se concentra no paradigma computacional de construção de algoritmos, ferramentas e software, com menor diálogo com a problematização em seu contexto de uso, não sendo ainda frequente o uso de teorias para explicar os usos, efeitos, sucessos e fracassos dos SI de forma mais ampla, com menores oportunidades de produção de conhecimento e de fortalecimento do corpo teórico da pesquisa em SI.

\section{Paradigmas epistemológicos ${ }^{6}$ de Pesquisa}

A ciência moderna baseia-se em um modelo de racionalidade desenvolvido para romper com o conhecimento medieval e aristotélico até então dominante [Santos, 1987, p.12]. Um paradigma que pressupõe que o único conhecimento válido é o que reside na

\footnotetext{
6 Epistemologia, também denominada de Filosofia da Ciência, é o ramo da filosofia que estuda os diferentes modos de pensar a produção de conhecimento humano
} 
objetividade, baseado em medições e modelos matemáticos, orientado pelos princípios da racionalidade formal ou instrumental que reduz o universo dos observáveis ao quantificável. O método Experimento deriva dessa visão objetiva da realidade, cuja máxima diz que "conhecer é medir o mundo". Esse método baseia-se na redução da complexidade, operacionalizado por meio do racionalismo cartesiano que busca dividir e classificar para depois determinar as relações causais entre os objetos, suas regularidades e padrões, as leis da natureza, visando explicar os fenômenos e prever seus comportamentos. A ciência moderna, cujas primeiras formulações estão assentadas no racionalismo cartesiano e no empirismo baconiano, veio a constituir-se no Positivismo no século XIX.

O paradigma epistemológico Positivista se tornou hegemônico, um modelo global que "transbordou do estudo da natureza para o estudo da sociedade. Tal como foi possível descobrir as leis da natureza, seria igualmente possível descobrir as leis da sociedade" (p.18). As ciências sociais, que emergiram no século XIX, foram constituídas com base na pressuposição de que é possível determinar, com rigor, as leis que governam deterministicamente a evolução das sociedades, cujas ações coletivas podem ser previstas, sendo necessário reduzir os fenômenos sociais às dimensões observáveis e mensuráveis. Contudo, uma vertente das ciências sociais, "durante muito tempo marginal mas hoje cada vez mais seguida, consistiu em reivindicar para as ciências sociais um estatuto epistemológico e metodológico próprio, com base na especificidade do ser humano e sua distinção polar em relação à natureza" (p.19). Dessa vertente, cujo argumento fundamental é que a ação humana é radicalmente subjetiva, resultou o paradigma epistemológico Interpretativo, do qual derivaram métodos qualitativos como Etnografia e Historiografia.

Já no século XX, diferenciando-se das práticas até então instituídas nas ciências sociais, foi desenvolvida a Pesquisa-ação, que se caracteriza numa abordagem epistemológica-metodológica de pesquisa que tem por objetivo realizar uma intervenção na realidade, não se limitando a compreender e descrever a realidade como se propõem os paradigmas Positivista e Interpretativo. "Se por muito tempo o papel da ciência foi descrever, explicar e prever os fenômenos, impondo ao pesquisador ser um observador neutro e objetivo, a pesquisa-ação adota um encaminhamento oposto pela sua finalidade: servir de instrumento de mudança social. Ela está mais interessada no conhecimento prático do que no conhecimento teórico" [Barbier, 2007, p53].

Outra abordagem baseada na prática, que visa modificar a realidade (e não apenas descrevê-la), emergiu na década de 1960, alavancada principalmente com a popularização dos computadores. Herbert Simon, em seu livro "As Ciências do Artificial" (1969), caracterizou "Design Science" (DS), a Ciência do Projeto ou Ciência do Artificial, como um paradigma epistemológico em que se produz conhecimento científico aliado ao desenvolvimento de artefatos. Ao colocar os estudos sobre o artificial no mesmo patamar das Ciências Naturais e Ciências Sociais, Simon apresentou e legitimou uma forma diferente de fazer ciência. Consideramos que tanto Pesquisaação quanto Design Science Research (DSR) são abordagens epistemológicasmetodológicas que tem por objetivo modificar a realidade, projetá-la, paradigma que denominamos Projetivo [Pimentel et al., 2017].

A área de SI notadamente teve origem nos estudos de computação, administração, pesquisa operacional e finanças [Hirschein e Klein, 2014]. Dada a afeição dessas áreas de conhecimento aos números nas suas primeiras décadas (1960, 
1970 e 1980), a pesquisa em SI se baseou em métodos quantitativos e buscava medir a uso da TI nas organizações de forma objetiva. Por outro lado, a partir da década de 1980, pesquisadores passaram a empregar métodos das ciências sociais para investigar questões subjetivas da TI [Markus e Robey, 1988][Orlikowski e Baroudi, 1991][Walsham, 1995].

Hirschheim e Klein (1989), inspirados no trabalho de Burrel e Morgan, propuseram uma taxonomia para categorizar as diferentes formas de se realizar pesquisa em SI (Figura 4), a saber: Funcionalismo, Relativismo Social, Estruturalismo Radical e Neo-humanismo.

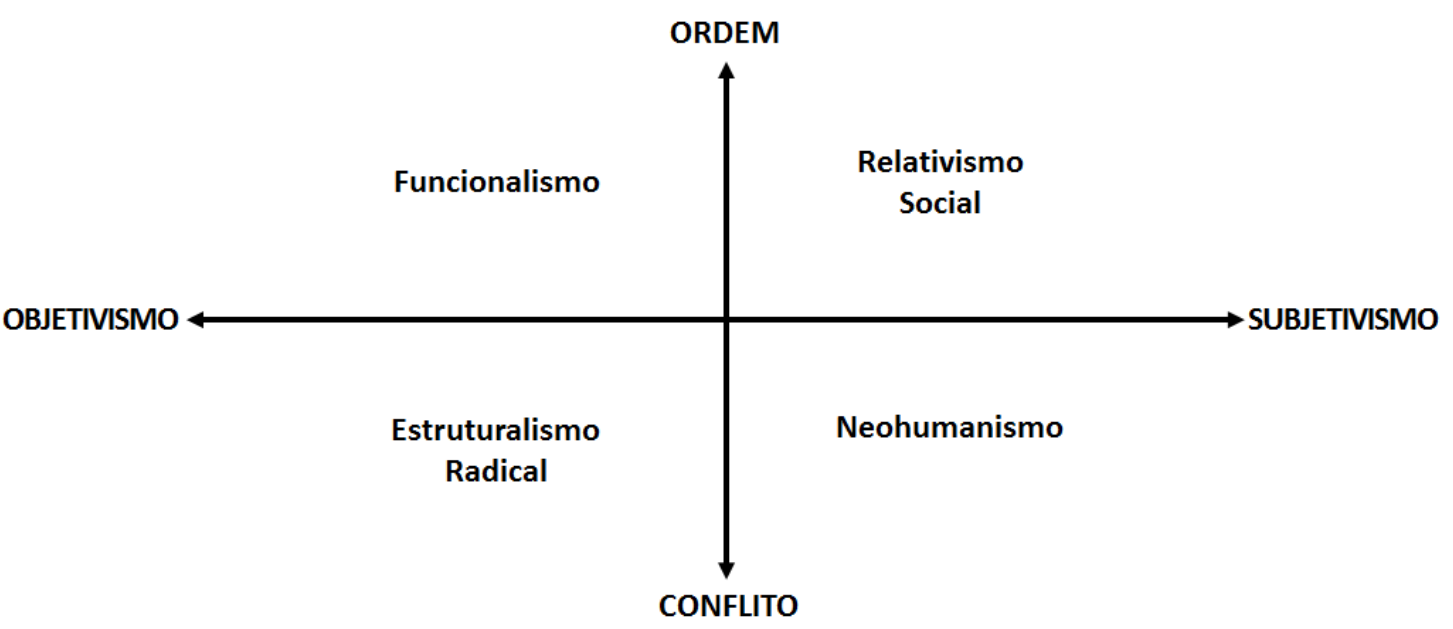

Figura 4 - Paradigmas de Pesquisa em SI

Fonte: Hirschheim e Klein (1989, p.1202)

Pesquisas funcionalistas propõem a realidade objetiva e que possa ser medida quantitativamente, mais comumente denominadas de positivistas. Por outro lado, as pesquisas inspiradas no relativismo social, também chamadas interpretativas, consideram que a realidade é construída socialmente por meio de processos de subjetivação. Por fim, as pesquisas inspiradas no Estruturalismo Radical e Neohumanismo pressupõem que o mundo é formado de conflitos materiais ou sociais, assim são chamadas de pesquisas críticas. Cada tipo de pesquisa apresentado aqui possui princípios filosóficos (ontológicos e epistemológicos), bem como métodos próprios. Desse modo, constituem estruturas internas de funcionamento e se estabelecem como o que podemos chamar de paradigmas de pesquisa. As pesquisas inspiradas nos paradigmas positivista e interpretativo tiveram maior desenvolvimento, enquanto pesquisas críticas quase não foram realizadas na área de SI.

Com a crescente crítica à dicotomia positivismo-interpretativo, alguns autores propuseram alternativas a essas abordagens, tal como a sociomaterialidade [Orlikowski e Scott, 2008], que no presente artigo denominaremos esse paradigma mais recente de Sociotécnico. A visão sociotécnica busca um novo enquadramento para o software "em que o técnico e o social constituem um movimento de 'co-modificação', somente percebido por uma abordagem concomitantemente social e técnica, por um olhar sociotécnico" [Cukierman, Teixeira e Prickladnicki, 2007]. A maioria dos trabalhos inspirados na abordagem sociotécnica refere-se a ambientes complexos com múltiplos 
atores, cujas preferências muitas vezes divergem, mostrando assim a dimensão política da implantação de um SI. Nessa abordagem, evita-se impingir uma teoria prévia sobre os dados, permitindo-se representar o caso de diferentes maneiras. Pode-se também notar que, nos estudos baseados na abordagem sociotécnica, a interação com o campo de pesquisa ocorre de maneira flexível.

Para analisar os paradigmas epistemológicos das pesquisas publicadas nos artigos da iSys, consideramos as categorias Positivista, Interpretativo, Projetivo, Crítico e Sociotécnico, conforme discutimos na presente seção. A identificação do método de pesquisa utilizado na pesquisa apresentada no artigo, também ajuda muito a identificar a perspectiva epistemológica - por exemplo, toda pesquisa em que se realiza um Experimento ou Survey, necessariamente está alinhada à perspectiva epistemológica Positivista. Em alguns artigos não foi possível identificar a perspectiva epistemológica e os classificamos como Ausente. Ao analisarmos os artigos, identificamos que uma pesquisa fez uso de múltiplos métodos de pesquisa, qualitativos e quantitativos, combinando as perspectivas positivista e interpretativa - nesse caso o classificamos como Misto. Apresentamos o resultado dessa análise na Figura 5.

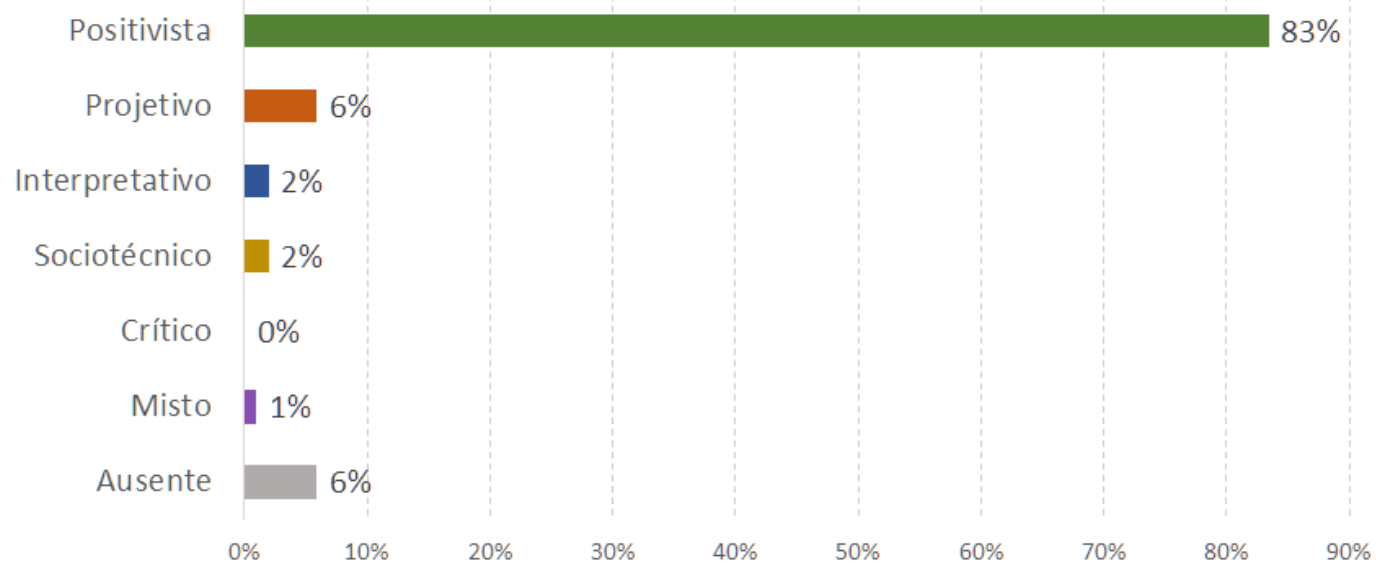

Figura 5. Frequência de artigos da iSys por paradigma epistemológico

Do resultado da análise, constatamos que o paradigma Positivista é o paradigma epistemológico hegemônico, ocorrendo em $89 \%$ das pesquisas publicadas na revista iSys. O paradigma Projetivo é o segundo mais frequente, ocorrendo em $6 \%$ das pesquisas. Poucas pesquisas foram produzidas na perspectiva Interpretativa $\mathrm{e}$ Sociotécnica, apenas 2 artigos em cada perspectiva. Nenhum artigo publicado na revista iSys apresentou pesquisa na perspectiva Crítica.

Para comparar com a literatura internacional os resultados aqui apresentados sobre a frequência dos paradigmas epistemológicos das pesquisas publicadas na revista iSys, optamos pelo estudo de Palvia e coautores (2017) que analisaram os artigos publicados entre 2004 e 2014 nas revistas internacionais mais importantes de Sistemas de Informação: MIS Quarterly (MISQ), que é dos principais periódicos sobre SI nos EUA; European Journal of Information Systems (EJIS), um dos principais periódicos europeu sobre SI, e Information \& Management (I\&M), uma das mais antigas e importantes revistas internacionais de SI. As categorias elaboradas por aqueles autores são ligeiramente diferentes das categorias que adotamos para análise dos artigos iSys.

Para estabelecer alguma relação entre a frequência dos paradigmas epistemológico das pesquisas publicadas na iSys, de acordo com a análise aqui 
apresentada, e as pesquisas publicadas nas principais revistas internacionais de Sistemas de Informação, apresentada por Palvia e coautores (2017), precisamos estabelecer um mapeamento entre as categorias dos dois sistemas taxonômicos empregados. Aqueles autores não reconhecem o paradigma Projetivo - sobre os 6 artigos que classificamos como Projetivo, podemos reclassificá-los em função da pesquisa empírica realizada, conforme já comentamos anteriormente (5 pesquisas Positivistas, e 1 Interpretativa). Aqueles autores também não reconhecem o paradigma Sociotécnico, e podemos realizar o mesmo tipo de tratamento dos dados, sendo que os 2 artigos que classificamos nesse paradigma podem ser reclassificados como Interpretativo. Sobre o paradigma Descriptive, segundo os autores: "A abordagem descritiva foi incluída para classificar artigos que descrevem apenas certos fenômenos sem tentar desenvolver ou testar a teoria" (p.220); podemos aproximar essa categoria ao que classificamos como Ausente, que também consideramos englobar a categoria Not Applicable daqueles autores. Feitas essas considerações e mapeamento entre as categorias, chegamos nos resultados representados na Figura 6:

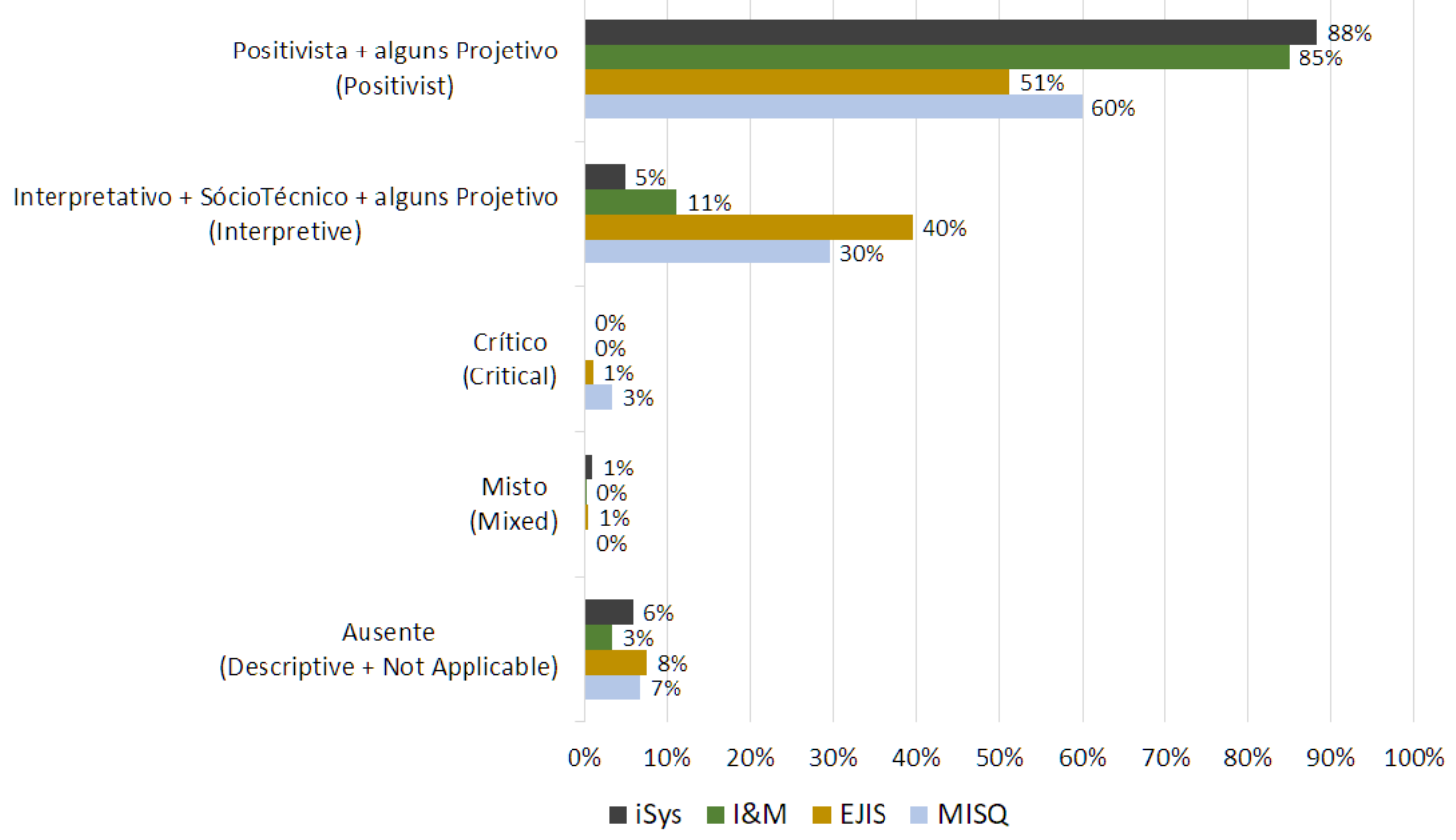

Figura 6 - Frequência, em função do Paradigma Epistemológico, das pesquisas publicadas na revista iSys de 2008 a 2017, e nas principais revistas internacionais de SI de 2004 a 2014 [Palvia et al., 2017]

Podemos constatar que o paradigma Positivista é o dominante nas pesquisas de SI, em todas as revistas. Contudo, nas revistas EJIS e MISQ, o paradigma Interpretativo aparece com frequência muito maior, em aproximadamente $1 / 3$ das pesquisas $(40 \% \mathrm{e}$ $30 \%$ ), enquanto na iSys esse percentual é reduzido, 5\%. No estudo de Orlikowski e Baroudi (1991), citado por Palvia e coautores (2017), é apontado que, no início da década de 1990 havia uma dominância das pesquisas positivistas $(97,8 \%)$ e algumas poucas pesquisas interpretativas $(3,2 \%)$, e não foram encontradas pesquisas inspiradas por abordagens críticas em SI. Esse panorama se alterou, como mostra Palvia e coautores (2017), pois há uma clara tendência de que mais pesquisas em Sistemas de Informação sejam realizadas no paradigma Interpretativo. 
Esse resultado nos faz pensar que a comunidade de pesquisadores brasileiros deve atentar para a boa oportunidade de realizar pesquisas interpretativas em SI. As abordagens interpretativas promovem a produção de conhecimento contextualizado, o que se mostra adequado para a área de pesquisa em SI.

Cabe destacar que a pesquisa inspirada na abordagem crítica, embora seja realizada em áreas correlatas como Administração e Economia, ainda não é muito frequente em Sistemas de Informação. Por fim, vale ressaltar que o paradigma Projetivo, embora não reconhecido na análise de Palvia e coautores (2017), tem sido alvo de interesse na área de Sistemas de Informação, principalmente a abordagem Design Science Research, que reconhecemos ser também uma tendência para as pesquisas em SI.

\section{Métodos de pesquisa}

Para analisar os métodos utilizados nas pesquisas publicadas nos artigos da iSys, consideramos, inicialmente, como possíveis categorias, o conjunto de métodos de pesquisa científica apresentados por Filippo, Pimentel e Wainer (2011): Experimento, Estudo de Caso, Survey, Pesquisa-ação, Etnografia e Teoria Fundamentada em Dados. Também incluímos a abordagem epistemológica-metodológica Design Science Research que vem se popularizando na área de Sistemas de Informação. Supúnhamos que alguns artigos não apresentariam uma pesquisa envolvendo uma avaliação por meio de um estudo empírico, e para esses casos classificaríamos o método como Ausente. Sabíamos que eventualmente nos depararíamos com outros métodos de pesquisa além desses previstos, e à medida que fôssemos encontrando iríamos adicioná-los às categorias de análise. Foram identificados: Simulação, Análise de Literatura, Revisão por Especialista, Historiografia e Método Misto. O significado de cada categoria está resumido a seguir:

- Experimento: Método para confirmar ou refutar uma hipótese sobre a relação entre duas variáveis supostamente independente e dependente. O experimento é realizado num ambiente laboratorial, artificial ou semi-artificial, onde se busca controlar as variáveis, que devem ser medidas com precisão. Os dados coletados devem ser analisados estatisticamente por meio de teste de hipótese.

- Estudo de Caso: Método para investigar um fenômeno em seu contexto real, em um ou poucos casos. Não se busca controlar possíveis variáveis envolvidas. São usados diversos instrumentos de pesquisa (questionários, entrevistas e análise de documentos, observação direta), e os dados são triangulados para fazer uma generalização analítica (não se busca validade estatística).

- Survey (Pesquisa de Levantamento): Método de pesquisa baseado em questionário para obter respostas de uma quantidade significativa de pessoas ou de toda a população (censo), com vistas a construir estatísticas sobre um tema, por exemplo, sobre as práticas adotadas por empresas ou por desenvolvedores de sistemas.

- Design Science Research (DSR): Abordagem epistemológica-metodológica para se produzir conhecimento científico por meio do desenvolvimento de algum artefato (sistema computacional, método, processo, modelo, arquitetura, framework, dispositivo eletrônico etc.).

- Pesquisa-ação: Método com duplo objetivo: realizar uma ação para promover uma melhoria numa organização ou comunidade, ao mesmo tempo em que se realiza uma pesquisa científica naquele contexto real. Quase sempre é realizado 
um processo iterativo, geralmente envolvendo as etapas diagnosticar-agiravaliar-refletir, para que a solução seja construída e refinada a cada ciclo da pesquisa.

- Etnografia: Método para se produzir conhecimento aprofundado por meio da observação direta do pesquisador que se insere num dado contexto real, com o objetivo de entender os valores e as práticas de uma dada organização ou comunidade. O pesquisador (con)vive com os sujeitos para entender como trabalham, o que sentem, como se relacionam.

- Teoria Fundamentada em Dados: Método em que são empregados procedimentos de análise de dados (por exemplo, análise de conteúdo) para fazer emergir, dos dados, novos conceitos que possibilitem a geração ou o refinamento de teorias. Para analisar os dados, o pesquisador não utiliza categorias prévias obtidas de um referencial teórico.

- Simulação: Método para simular o comportamento de um sistema ou seus processos. Requer um modelo operatório, com variáveis e parâmetros, a partir do qual são produzidas os dados de interesse da pesquisa.

- Análise de Literatura: Método de pesquisa baseada na análise da literatura, incluindo mapeamento e revisão sistemática da literatura. Tem por objetivo reunir, analisar e sintetizar os dados dos estudos primários obtidos de um conjunto de artigos.

- Revisão por Especialista: Método para realizar uma avaliação por especialistas (por formação ou experiência) considerados capazes de fornecer opinião confiável sobre o artefato proposto ou sobre um tema em investigação.

- Historiografia: Método em que o pesquisador visa escrever uma história acerca de um tema ao longo de um período específico. Faz uso de evidências e documentos para construir uma narrativa baseada em sua interpretação e visão de mundo.

- Método Misto: Quando o pesquisador utiliza uma composição de métodos para realizar a pesquisa.

- Ausente: Quando não encontramos um estudo empírico no artigo. Por exemplo, artigos que apresentam uma técnica sem apresentar uma avaliação empírica do uso da técnica elaborada. Consideramos "Prova de Conceito", citado por dois artigos, como "Ausente" de método de pesquisa porque essa técnica serve para explicar melhor e ilustrar o que está sendo proposto, contudo, não envolve uma avaliação empírica como nos demais métodos. Nessa categoria também foram classificadas experiências e práticas de ensino em SI.

Ao analisar os artigos em função do método de pesquisa, consideramos o método que foi declarado pelos próprios autores em cada artigo. Nos artigos em que o método de pesquisa não foi explicitado pelos próprios autores, nós mesmos classificamos o método utilizado, quando presente. Apresentamos o resultado dessa análise na Figura 7: 


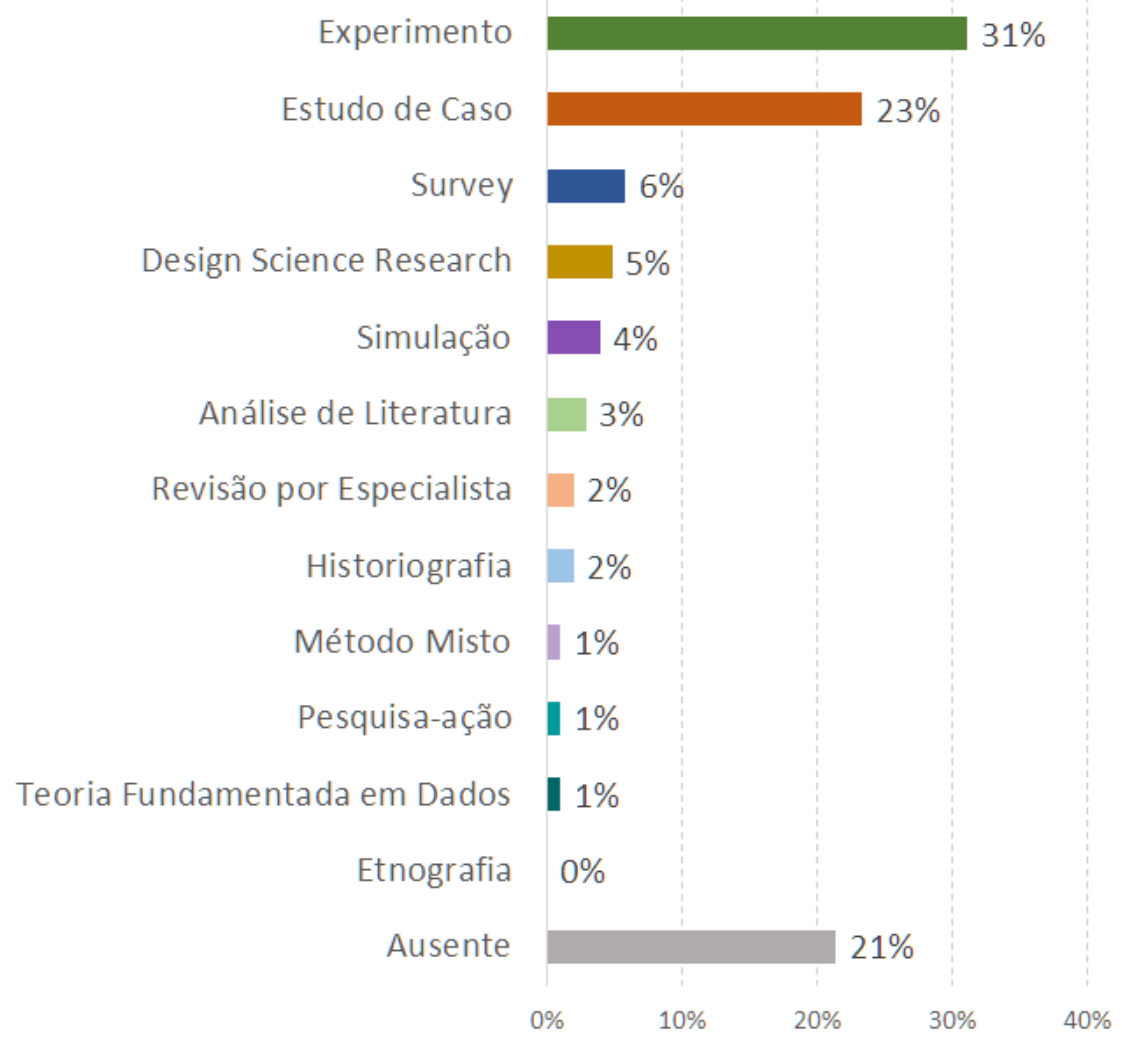

Figura 7 - Análise dos artigos iSys (2008-2017) em função do Método de Pesquisa

Do resultado da análise, constatamos que Experimento é o método mais utilizado para a realização das pesquisas publicadas na revista iSys (31\% dos artigos), seguido do método Estudo de Caso (23\% dos artigos). A maioria dos artigos publicados na revista utilizou um desses dois métodos (53\% dos artigos), sendo que apenas $1 / 4$ dos artigos empregou algum outro método de pesquisa (25 artigos, 24\%). Aproximadamente $1 / 5$ dos artigos não realizou uma pesquisa empírica (método Ausente em 22 artigos, $21 \%)$.

Em uma comparação das categorias apresentadas acima com as análises de Palvia e coautores (2017), é notável que Estudo de Caso é um método muito utilizado tanto nas pesquisas publicadas nas revistas internacionais quanto na iSys. Esse é um resultado coerente, porque muitas pesquisas em Sistemas de Informação são voltadas para um determinado contexto real, geralmente uma empresa que faz uso ou que desenvolve TI. Cabe ressaltar que o método Estudo de Caso, embora possa ser empregado em qualquer perspectiva epistemológica, dos artigos publicados na revista iSys que declararam ter realizado um Estudo de Caso, 92\% desses artigos (22 dos 24 artigos) o empregaram numa perspectiva Positivista; apenas 1 artigo realizou um Estudo de Caso na perspectiva Interpretativa e 1 artigo na perspectiva Sociotécnica. Vale também comentar que na abordagem Projetiva, é necessário realizar um estudo empírico, e esse estudo pode ser classificado nas demais perspectivas epistemológicas, e identificamos que, dos 6 artigos com essa abordagem, 5 realizaram pesquisa Positivista e 1 realizou pesquisa Interpretativa.

Enquanto nas revistas internacionais o outro método mais utilizado é Survey, muito comum para avaliação de efeitos e impactos da tecnologia, na iSys o outro 
método mais utilizado é Experimento, mais comum para a avaliação da eficácia de soluções computacionais. Métodos Qualitativos, como Etnografia, Pesquisa-ação e Historiografia, bem como os métodos baseados na Análise da Literatura (mapeamento e revisão sistemática da literatura), apresentam-se como oportunidades para serem mais utilizados pelos pesquisadores em SI que publicam na iSys. O uso da abordagem Design Science Research é já presente nas pesquisas em SI, assim como os demais métodos Teoria Fundamentada em Dados e Simulação - embora ainda pouco frequentes.

$\mathrm{Na}$ revista iSys 23\% foram classificados como "Ausente" quanto ao método de pesquisa. Esses artigos representam reflexões dos pesquisadores quanto a técnicas e práticas de ensino em Sistemas de Informação. Embora não tenham apresentado o percurso metodológico de maneira específica, tais reflexões são fundamentais para promover o debate e expandir os horizontes da comunidade de SI.

\section{Conclusão}

Neste artigo relatamos uma análise das publicações dos 10 primeiros anos da iSys revista científica nacional na área de Sistemas de Informação, fruto de ações estratégicas de consolidação da área de pesquisa em SI no Brasil, atualmente mantida pela Comissão Especial de Sistemas de Informação da Sociedade Brasileira de Computação.

Nossa análise delineia um retrato da produção científica disseminada por meio da iSys do ponto de vista de como a comunidade de pesquisadores da revista têm organizado seu pensamento científico com respeito à aplicação da tríade teoriaepistemologia-metodologia nas pesquisas, tríade esta, necessária para a produção de conhecimento científico relevante em qualquer área de conhecimento. Também buscamos compreender qual a concepção da Tecnologia de Informação nas pesquisas publicadas nessa revista. Em nossa análise, discutimos a produção de conhecimento científico publicada na iSys levando em consideração outros trabalhos - nacionais e internacionais - explorando similaridades, distinções e oportunidades.

Compreendendo os objetivos da pesquisa em Sistemas de Informação como a investigação das possibilidades de soluções tecnológicas sistêmicas para problemas complexos no mundo real em diferentes domínios de aplicação, podemos relatar, como conclusão de nossa análise, que os objetivos de pesquisa da comunidade de pesquisa ambientada ao redor da iSys oscilam principalmente entre pesquisas de caráter computacional (sem problematização do contexto de aplicação), pesquisas de caráter nominal (o objeto de estudo não é diretamente o artefato TI) e pesquisas para o projeto de ferramentas para uso em contextos específicos de caracterização simplificada (o objetivo principal é a construção da ferramenta, sendo considerados secundários os impactos de seu uso). Essa forma de olhar o artefato SI se alinha com o posicionamento epistemológico positivista dessa comunidade, indicado pela alta frequência de uso dos métodos de pesquisa de experimentação e estudos de caso com perspectiva positivista. Esta característica reducionista (positivista) e experimental incide na produção científica desta comunidade, caracterizada pela criação e aplicação de técnicas, modelos e frameworks, com ainda muito pouco foco na formulação de corpo teórico na área de SI.

Para uma comunidade que pretende ser protagonista na pesquisa em SI no país, bem como dialogar com a produção científica internacional, esta análise aponta para desafios e oportunidades significativos. Um desafio é reconhecer o potencial científico decorrente de uma abertura a paradigmas epistemológicos que compreendam a 
complexidade e a multiplicidade do mundo real, essencial para a natureza das pesquisas na área de Sistemas de Informação. Consideramos ser necessário pensar em outros valores que inspirem pesquisas mais subjetivas e não reducionistas. Nesse sentido, deve-se valorizar a contextualização, o raciocínio dialógico e a pluralidade de interpretações. Ademais, a multiplicidade de paradigmas nos convida a praticar outros métodos de pesquisa ainda pouco utilizados pela comunidade de SI. Cabe aqui ressaltar que um paradigma não é superior a outro, mas deve ser compreendido dentro de seus pressupostos epistemológicos. Aqui não estamos querendo fazer simplesmente uma apologia a paradigmas de pesquisa específicos, mas destacar que a pluralidade de paradigmas torna a comunidade de pesquisa em SI ainda mais competente na resolução de problemas reais, como também sólida e hábil científica e academicamente, com propriedade para articulação com outras áreas de conhecimento nacionais $\mathrm{e}$ internacionais.

Com a reflexão sobre os resultados dessa análise, esperamos contribuir com a comunidade de pesquisa em SI ligada à Computação, em sua agenda estratégica de robustecer seu impacto científico e acadêmico nos anos vindouros. Acreditamos que uma possível limitação da análise aqui apresentada está no fato de a mesma considerar como referência comparativa, um subconjunto de periódicos da área de SI que, embora reconhecidos pela área, podem representar comunidades com histórico e características distintas da comunidade científica da iSys. Outra limitação é o caráter interpretativo e manual do processo de análise, baseado na convergência de entendimento a respeito dos critérios de avaliação pelos autores. Como trabalhos futuros, é necessário realizar a análise relacionando de forma mais aprofundada as grandes questões de pesquisa da comunidade de SI no Brasil, bem como a própria dinâmica de produção de conhecimento dessa comunidade. Além disso, gostaríamos de ver o conteúdo deste artigo sendo debatido e criticado amplamente durante as atividades do Simpósio Brasileiro de Sistemas de Informação, dentro dos programas de pós-graduação e grupos de pesquisa nacionais na área de SI, pelos editores e revisores de periódicos ligados ao tema, e por colegas de outras áreas de conhecimento, inspirando uma construção e reflexão coletiva e contínua de nosso fazer científico.

\section{Agradecimentos}

Renata Araujo é bolsista de produtividade em desenvolvimento tecnológico e extensão inovadora pelo CNPq sob número 305060/2016-3.

\section{Referências}

Araujo, R.M., Maciel, R.S. e Boscarioli, C. (2017) "I GranDSI-BR: Grandes Desafios de Pesquisa em Sistemas de Informação no Brasil (2016-2026)". Relatório Técnico. Comissão Especial de Sistemas de Informação (CESI) da Sociedade Brasileira de Computação (SBC). $\underline{\text { http://www2.sbc.org.br/ce- }}$ si//arquivos/grandsi.pdf (acesso em julho de 2017). [GS Search]

Araujo, R., Ralha, C., Graeml, A. e Cidral, A. (2015) "Comunidade de Pesquisa em Sistemas de Informação no Brasil na perspectiva do Simpósio Brasileiro de Sistemas de Informação". Revista Brasileira de Sistemas de Informação (iSys), v. 8, n 1, p. 5-17. http://seer.unirio.br/index.php/isys/article/view/5136 [GS Search]

Barbier, R. (2007) A pesquisa-ação. Brasília: Liber Livro.

Barros, M., Diniz, M., Araujo, R. e Cidral, A. (2008) Editorial. Revista Brasileira de 
Sistemas de Informação (iSys), v.1, n.1, p.i-iii. Rio de Janeiro: CESI/SBC. http://seer.unirio.br/index.php/isys/article/view/212

Barros, M., Diniz, M., Araujo, R. e Cidral, A. (2009) Editorial. Revista Brasileira de Sistemas de Informação (iSys), v.2, n.1, p.i-ii. Rio de Janeiro: CESI/SBC. http://seer.unirio.br/index.php/isys/article/view/452

Capra, F. e Luisi, P L. (2014), A Visão Sistêmica da Vida, Editora Cultrix, 1a edição.

Cidral, A., Ralha, C., Cáceres, E., Santoro, F., Audy, J., Barros, M., Furtado, O. e Araujo, R. (2009) "Sistemas de Informação no Brasil - Desafios e Oportunidades". http://www2.sbc.org.br/ce-si//arquivos/desafios_SI 2009 05_19.pdf. Maio. (acesso em julho de 2017). [GS Search]

Cukierman, H. L., Teixeira, C. e Prikladnicki, R. (2007) "Um Olhar Sociotécnico sobre a Engenharia de Software". Revista de Informática Teórica e Aplicada, v. 14, n. 2, p. 199-299. http://www.seer.ufrgs.br/rita/article/viewFile/5696/3547 [GS Search]

Filippo, D., Pimentel, M., \& Wainer, J. (2011). Metodologia de pesquisa científica em sistemas colaborativos. In M. Pimentel \& H. Fuks (Eds.) Sistemas Colaborativos $\begin{array}{lllll}\text { (capítulo 23). Rio de Janeiro: } & \text { SBC/Elsevier. }\end{array}$ https://www.dropbox.com/sh/ftcq79y2aqq16u4/sFxQwE8iO

Grover, V. e Lyytinen, K. (2015) "New State of Play in Information Systems Research: The Push to the Edges", MIS Quarterly, v. 39 n. 2, pp. 271-296. http://aisel.aisnet.org/misq/vol39/iss2/3/ [GS Search]

Heeks, R. e Bailur, S. (2007) "Analyzing e-government research: Perspectives, philosophies, theories, methods and practice". Government Information Quarterly, v. 24, p. 243-265. doi: 10.1016/j.giq.2006.06.005 [GS Search]

Hirschheim, R. e Klein, H. K. (1988) "Four Paradigms of Information Systems Development". Communications of the ACM, v. 32, n. 10, p. 1199-1216. doi: $\underline{10.1145 / 67933.67937}$ [GS Search]

Latour, B. (1997) Ciência em Ação: Como seguir cientististas e engenheiros sociedade afora. São Paulo: Editora Unesp.

MarkuS, M. L. e Robey, D. (1988) Information Technology and Organizational Change: Causal Structure in Theory and Research, Management Science, v. 34, n. 5, pp. 583-598. doi: 10.1287/mnsc.34.5.583 [GS Search]

Morin. E. (2005), Introdução ao Pensamento Complexo, Editora Sulina, 5 a edição.

Orlikowski, W. J. e Baroudi, J. J. (1991) "Studying Information Technology in Organizations: Research Approaches and Assumptions". Information Systems Research, v. 2, n. 1, pp. 1-28. doi: 10.1287/isre.2.1.1 [GS Search]

Orlikowski, W. J, e Iacono, C. S. (2001) "Desperately Seeking the "IT" in IT Research-A Call to Theorizing the IT Artifact". Information Systems Research, v 12, n 2, p. 121-134. doi: 10.1287/isre.12.2.121.9700 [GS Search]

Orlikowski, W. J. e Scott, S. V. (2008) Sociomateriality: challenging the separation of technology, work and organization. The Academy of Management Annals, v. 2 n. 1, pp. 433-474 [GS Search]

Palvia, P., YK, C. P., Kakhki, M. D., Ghoshal, T., Uppala, V., \& Wang, W. (2017). A decade plus long introspection of research published in Information \& 
Management. Information \& Management, 54(2), 218-227. doi: 10.1016/j.im.2016.06.006 [GS Search]

Palvia, P., Mao, E., Salam, A. F. e Soliman, K. S. (2003) "Management information systems research: what's there in a methodology?" Commun. Assoc. Inf. Syst., 11, p. 288-310. http://aisel.aisnet.org/cgi/viewcontent.cgi?article=2703\&context $=$ cais [GS Search]

Pimentel, M., Filippo, D., Calvão, L.D., \& Silva, A. R. (2017). "Design Science Research: pesquisa científica para o desenvolvimento de artefatos inovadores". In: Pesquisa e Inovação: visões e interseções. editado por R. M. Araujo \& L. O. V. Chueri. Rio de Janeiro, RJ: Publit.

Recker, J. (2013) Scientific Research in Information Systems, Springer, 1a edição.

Santos, B.S. (1987) Um discurso sobre as ciências. Afrontameto: Porto, Portugal.

Simon, H (1969). The sciences of the artificial, 3. ed. Cambridge: MIT Press, 1996.

Walsham, G. (1995) Interpretive case studies in IS research: nature and method. European Journal of Information Systems, v. 4, p. 74-81. doi: 10.1057/ejis.1995.9 [GS Search] 